\title{
Distinguishing clockwise from counterclockwise: Does it require mental rotation?
}

\author{
MICHAEL C. CORBALLIS \\ University of Auckland, Auckland, New Zealand
}

\begin{abstract}
In three experiments, subjects were timed as they judged whether stimuli, presented in different angular orientations, represented clockwise or counterclockwise directions. In each experiment, there was also a control condition in which the subjects were required to make mirrorimage judgments relative to some canonical orientation. Analysis of reaction times suggested that, in the control tasks, the subjects generally rotated the stimuli mentally to the canonical orientation before making their decision. Mental rotation was invoked less frequently in the case of the experimental tasks, suggesting at least limited access to an orientation-free code representing the difference between clockwise and counterclockwise. This was most evident in Experiment 1, where the stimuli represented 1-h jumps of a hand on a clock face. It was less so in Experiment 2, where direction of motion was indicated in a static display. In Experiment 3, only a few subjects proved able to use an orientation-free, clockwise versus counterclockwise rubric in order to discriminate normal from backward letters.
\end{abstract}

In some tasks involving decisions about rotated shapes, subjects apparently mentally rotate each shape to some upright or canonical orientation before making a decision. In decisions as to whether rotated alphanumeric characters are normal or backward, for instance, reaction times (RTs) increase sharply with the angular departure of each character from the normal upright, implying mental rotation to the upright before the decision is made (Cooper $\&$ Shepard, 1973). Similar results have been obtained for decisions as to whether drawings of a human hand depict a left or a right hand (Cooper \& Shepard, 1975) or whether arbitrary shapes are in a standard or mirrorreversed form (Cooper \& Podgorny, 1976; Eley, 1982). As these examples illustrate, mental rotation seems to play a critical role in the discrimination of mirror images, implying that the parity or "handedness" of a shape can be resolved only if the shape is aligned with egocentric spatial coordinates (Corballis, 1982; Corballis \& Beale, 1976; Hinton \& Parsons, 1981).

By contrast, mental rotation does not seem to be involved in decisions about the identity of rotated alphanumeric characters (Corballis \& Nagourney, 1978; Corballis, Zbrodoff, Shetzer, \& Butler, 1978; White, 1980) or of rotated letter-like symbols (Eley, 1982). Mental rotation may play a role in the identification of rotated natural objects (Schwartz, 1981), although that role seems to be transitory (Jolicoeur, 1985). Paradoxically, however, subjects can identify normal characters more rapidly than mirror-image ones, regardless of orientation

I thank Pierre Jolicoeur, Janice E. Murray, and Lawrence Parsons for helpful comments. Requests for reprints should be sent to Michael C. Corballis, Department of Psychology, University of Auckland, Private Bag, Auckland, New Zealand. and even though mental rotation is not invoked (Corballis \& Nagourney, 1978; Corballis et al., 1978). This is true not only of adults, but also of 11- to 13-year-old children, including those with specific reading disability (Corballis, Macadie, Crotty, \& Beale, 1985), a group often considered to have special difficulty with mirror-image discrimination (Corballis \& Beale, 1976; Orton, 1937).

It might be argued that the more rapid identification of normal letters is simply a matter of familiarity. It has been suggested, in fact, that shapes are stored both in the original and in a weaker mirror-image form (e.g., Corballis \& Beale, 1976; Orton, 1937); this can explain both why subjects are often initially confused by mirror images and why the stronger normal version normally prevails. What needs further explanation, however, is how recognition latency can be very largely independent of angular orientation, but quite strongly dependent on parity. What kind of shape code can be orientation-free, yet retain information about parity?

One possible answer-perhaps the only logical answer-is that parity can be coded with reference to either a clockwise or a counterclockwise torque, as manifest, for instance, in a spiral or in a direction of angular motion (Corballis, 1988). The notion that parity might be spirally coded has been invoked in developmental biology to explain how the left and right sides of the embryo come to be systematically distinguished, even though the sagittal plane is determined arbitrarily (Bateson, 1980; Lepori, 1969).

These considerations suggest that there may be an orientation-free code, in the form of a torque or a spiral, that underlies the more rapid recognition of normal than of backward characters regardless of their orientations. This paper explores the possibility that such a code might 
be available for explicit discrimination of clockwise from counterclockwise directions of motion, in a manner that requires neither mental rotation nor reference to a canonical orientation.

In Experiment 1, the stimuli were dynamic displays, representing the jump of a hand on a clock face, and the subjects judged whether each jump was clockwise or counterclockwise. In Experiment 2, the stimuli were static displays, with direction of motion represented by an arrow on the end of a line and at right angles to it. In Experiment 3 , subjects were encouraged to think of the letters $F, P$, and $R$ as representing either clockwise or counterclockwise directions of motion, as determined by the upper loop of the $\mathrm{P}$ and $\mathrm{R}$ or the upper cross stroke of the F. In each experiment, there was a control condition in which the stimuli were the same, but the task encouraged mental rotation. This provided a standard against which to assess the incidence of mental rotation in the experimental tasks.

\section{EXPERIMENT 1}

\section{Method}

Subjects. The subjects were 9 women and 5 men, ranging in age from 21 to 47 years. All described themselves as right-handed, except for 1 left-handed woman.

Stimuli and Equipment. The stimuli were generated by an Apple Ile computer and presented on a fast-phosphor green screen. Stimulus presentations were synchronized with a 50-cycle per second frame rate, according to the procedures described by Cavanagh and Anstis (1980).

The stimuli were presented against a clock face represented by 12 dots arranged in a circle at $30^{\circ}$ intervals (i.e., marking the positions of the hours), with a radius of $30 \mathrm{~mm}$. The stimuli were viewed from a distance of about $70 \mathrm{~cm}$. A line was drawn from the center of the clock face to one of the dots to represent a hand on the clock face. A given line was presented for seven frames, or approximately $140 \mathrm{msec}$, and was followed for an additional seven frames by another line in a neighboring orientation, representing a jump of $30^{\circ}$ either clockwise or counterclockwise. The screen then went blank. In the 72 experimental trials, each of the 12 starting orientations was chosen six times, with three jumps clockwise and three counterclockwise. The 72 trials were presented in a different random order to each subject.

The subjects responded by pressing designated keys on the computer console. Reaction time was measured from the offset of the stimulus by means of a machine language timing routine.

Tasks. There were two tasks. In the experimental task, Task E, the subjects were required to press the $\mathrm{C}$ key for clockwise jumps and the $\mathrm{X}$ key for counterclockwise jumps; these keys are adjacent on the bottom row of the console. In the control task, Task C, they were required to press the $\mathrm{N}$ key if the direction of the jump was such that it would move to the right as it passed the 6:00 position on the clock face, and the B key if the direction was to the left past the 6:00 orientation. These keys are also adjacent on the bottom row of the console, with the $\mathrm{N}$ key to the right of the $\mathrm{B}$ key, and the labels "LEFT" and "RIGHT" were affixed to the space bar immediately below the keys.

Task C was intended as a "mental-rotation" control, on the expectation that the subjects would mentally rotate the stimuli to the 6:00 position in order to make their decisions. They were encouraged not to simply treat the tasks as the same, since it is, in fact, possible to respond to Task $\mathrm{C}$ by making a clockwise-counterclockwise decision, and to Task $\mathrm{E}$ by making a left-right decision. As a disincentive to recode in this fashion, the $6: 00$ position was chosen as the canonical orientation in Task $\mathrm{C}$, which meant that the leftward key was used for clockwise and the rightward key for counterclockwise motion, reversing the mapping required for Task E.

Procedure. Each subject performed both tasks, half beginning with Task $\mathrm{E}$ and half with Task $\mathrm{C}$. On each task, each subject was first given 10 practice trials, with stimuli chosen randomly from the 24 possible stimuli. They were then given the 72 experimental trials.

Before each trial, the subject sat with the index finger of each hand resting lightly on the appropriate response keys. Stimulus presentation was controlled by the subject, and was initiated by a press on either key. The stimulus appeared $500 \mathrm{msec}$ after the keypress. If the subject made an error, the stimulus was repeated at the end of the series. The subjects were told to respond as quickly as was consistent with high accuracy.

\section{Results}

In analyzing the results, orientations were measured clockwise from the downward (or 6:00) orientation, which was the presumed canonical orientation for Task $C$. The orientation of each jump was defined as its midpoint; thus, for instance, a jump between $0^{\circ}(6: 00)$ and $30^{\circ}$ (7:00) was considered to be located at $15^{\circ}$.

Errors. The subjects made errors on $8.23 \%$ of trials. Errors were subjected to analysis of variance, in which the independent variables were order, task, orientation, and direction, but there were no significant effects or interactions. There were, nevertheless, somewhat fewer errors on Task $\mathrm{E}(7.24 \%)$ than on Task $\mathrm{C}(9.22 \%)[F(1,12)$ $=1.92, M S e=0.3095$, n.s.]. There were small positive correlations between mean numbers of errors and mean RTs across the 12 orientations; for Task E the correlations were .38 and .23 for clockwise and counterclockwise jumps, respectively, and for Task $C$ the correlations were .31 and .56 for leftward and rightward jumps, respectively. These data suggest that the $R T$ trends, analyzed below, were not contaminated by speed-accuracy tradeoffs.

Reaction times. An analysis of variance was also carried out on RTs, with the same independent variables. The mean RT was significantly longer for Task C (643 msec) than for Task $\mathrm{E}(456 \mathrm{msec})[F(1,12)=9.47, M \mathrm{Me}=$ $620,369, p<.01]$, suggesting that, as a group, the subjects did not treat the two tasks as the same. The effect of orientation was not significant $[F(11,132)=1.50, M S e$ $=67,769]$, nor was there a significant interaction between task and orientation $[F(11,132)=1.40, \mathrm{MSe}=53,777]$. There were, however, two significant effects involving direction: One was the effect of direction itself $[F(2,24)$ $=5.77, M S e=59,870, p<.01]$, and the other was the interaction between direction and orientation $[F(22,264)$ $=2.67, M S e=59,155, p<.001]$. Since these last two effects were nested within tasks, separate analyses were carried for each task. 
For Task $\mathrm{E}$, the effect of direction was significant $[F(1,12)=7.33, M S \mathrm{e}=90,490, p<.05]$, with RT for clockwise $(411 \mathrm{msec})$ shorter than that for counterclockwise $(500 \mathrm{msec})$. The interaction between direction and orientation was not significant $[F(11,132)=1.09, \mathrm{MSe}$ $=36,098]$. Orientation was also significant $[F(11,132)$ $=2.06, M S e=51,574, p<.05]$, even though in the main analysis it was not significant and did not interact with task.

For Task $\mathrm{C}$, the effect of direction was not significant $[F(1,12)=0.93, M S e=29,251]$, and in fact mean RT for leftward motion $(634 \mathrm{msec})$ was slightly shorter than that for rightward motion $(652 \mathrm{msec})$; leftward motion corresponded to clockwise motion, which is the more familiar on a clock face. The effect of orientation was not significant $[F(11,132)=1.01, M S e=69,971]$, which might suggest that this task was not successful in inducing mental rotation. However, there was a significant interaction between direction and orientation $[F(11,132)$ $=3.37, M S e=82,211, p<.001]$. Figure 1 shows the effect of orientation for each direction for each task, and for Task $\mathrm{C}$ it is clear that RT was influenced not only by the orientation of each jump, but also by its direction.

Fitting mental-rotation functions. To test for mental rotation, contrasts were defined to represent idealized mental-rotation functions in which RT is assumed to be a linear function of the angular distance of each orientation from some canonical orientation. If we suppose that the canonical orientation is at $0^{\circ}$ (or 6:00), as one might expect for Task $\mathrm{C}$, the idealized contrast representing mental rotation consists of the coefficients $-5,-3,-1$, $1,3,5,5,3,1,-1,-3$, and -5 , representing the orientations in $30^{\circ}$ steps clockwise from $15^{\circ}$ to $345^{\circ}$. Cyclic permutations of these coefficients represent $30^{\circ}$ increments in the location of the canonical orientation. The contrast was fitted to the mean RTs at each orientation, and permuted through the 12 locations of the canonical orien- tation, from $0^{\circ}$ to $330^{\circ}$. The proportion of variance accounted for was computed for each permutation, and the permutation corresponding to the maximum proportion was chosen to define the best fitting mental-rotation function, with its associated canonical orientation. The estimated rate of mental rotation was also computed from the best fitting function.

For Task $\mathrm{E}$, the best fitting function corresponded to a canonical orientation of $210^{\circ}$, implying mental rotation to about the 1:00 orientation. However, this hypothesis accounted for only $48.39 \%$ of the variance between orientations, and the estimated mental-rotation rate from the best fitting function was 1,250 degrees per second (dps), which is well above the typical estimate of some 300-700 dps (e.g., Cooper \& Shepard, 1973; Shepard \& Hurwitz, 1984). This suggests that the variation in RT between orientations was not due to mental rotation-or, at least, not entirely. It is possible simply that direction of rotation is most easily judged at the beginning of the conventional clock cycle.

For Task $\mathrm{C}$, the functions were fitted separately for the two directions of motion, since the direction $X$ orientation interaction was significant. For jumps representing leftward motion past the 6:00 position (clockwise jumps), the best fitting function corresponded to a canonical orientation of $270^{\circ}$ (or $3: 00$ ), accounted for $56.66 \%$ of the variance, and represented an estimated mental-rotation rate of $563 \mathrm{dps}$. For rightward jumps, the canonical orientation was at $60^{\circ}$ (or 8:00), the percent of variance accounted for was $50.98 \%$, and the estimated rate was $794 \mathrm{dps}$. These values are closer to what one might expect if subjects were mentally rotating, with mental rotation quite strongly influenced by the direction of the jump. The canonical orientation was thus some $60^{\circ}-90^{\circ}$ in advance of the 6:00 position with respect to the direction of the jump, suggesting that subjects may have extrapolated the jump prior to initiating mental rotation.

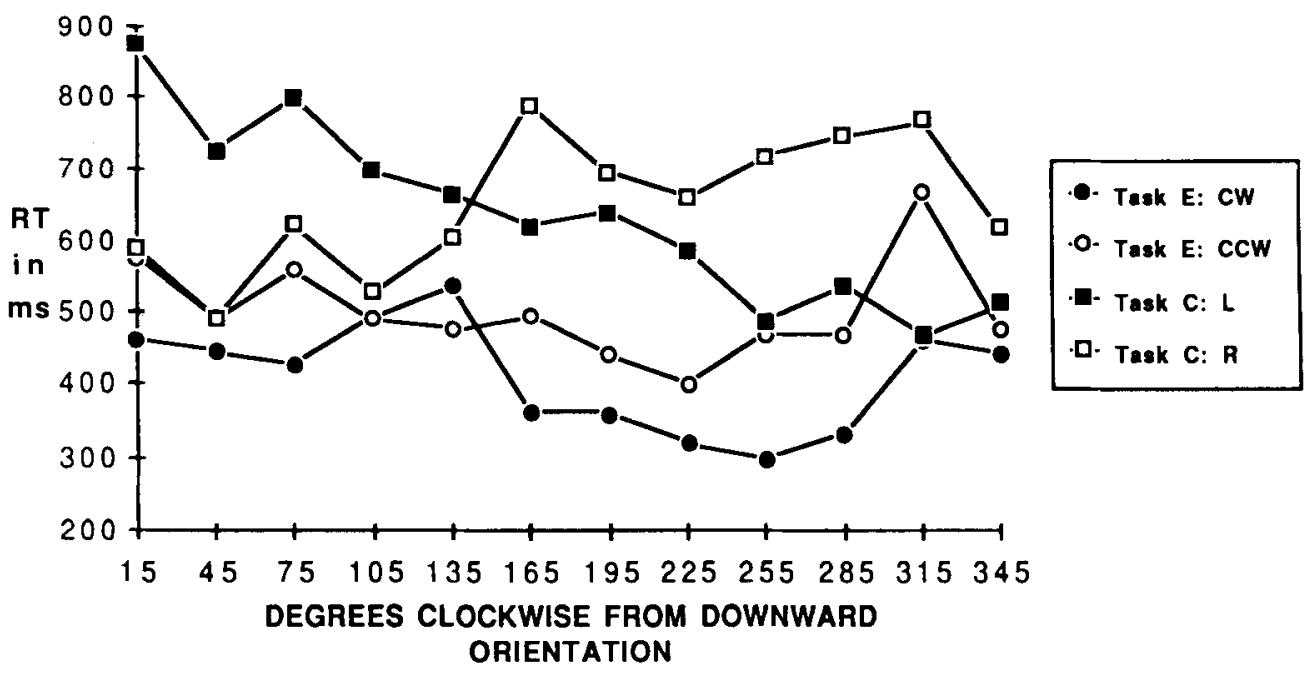

Figure 1. Mean RT as a function of angular distance from downward (or 6:00) orientation, for each direction in each task in Experiment 1. 
Fits to individual data. One possible reason why the functions are not particularly well fit by mental-rotation functions could be that the canonical orientation differed from subject to subject. Consequently, the idealized mental-rotation function was fitted to the mean RTs for each individual subject, separately for each direction on each task, with the orientations cyclically permuted in order to establish the best fit and the best estimate of the canonical orientation. The canonical orientation, the proportion of variance accounted for, and the estimated mental-rotation rate derived from each of these best fitting functions are shown in Table 1, along with the mean RT in each case.

It is clear that the idealized mental-rotation function provided the better fit more often with Task $C$ than with Task E. Suppose we define a subject as a mental rotator if the following (rather lenient) conditions hold for both directions of motion on a given task: (1) the proportion of variance accounted for is at least .3, and (2) the estimated rate of mental rotation is less than $800 \mathrm{dps}$. Nine of the 14 subjects met these criteria on Task $C$, compared with only 1 on Task E. One other subject (Subject 5) was clearly idiosyncratic in that her RTs were abnormally long, and were so variable that the orientation function showed no systematic trends.

For Subject 4, whose RTs in Task E conformed reasonably well to the mental-rotation function, the canonical orientation was at $210^{\circ}(1: 00)$ for clockwise jumps and $180^{\circ}(12: 00)$ for counterclockwise jumps. That is, this subject tended to mentally rotate the stimuli to the top or top right of the clock face. For Task $C$, there was considerable variability in the location of the canonical orientation. However, for 13 of the 14 subjects the canonical orientation for leftward jumps lay between $180^{\circ}$ and $0^{\circ}$ on the right-hand side of the clock face, and for 11 of the 14 the canonical orientation lay between $0^{\circ}$ and $180^{\circ}$ on the left-hand side. Again, this can be interpreted to mean that the motion of the jump was extrapolated prior to mental rotation.

Analysis of adjusted orientation functions. Next, a comparison between tasks was undertaken in which the orientations for each subject at each direction on each task

Table 1

Individual Parameters in Experiment 1

\begin{tabular}{|c|c|c|c|c|c|c|c|c|c|c|}
\hline \multirow[b]{2}{*}{ Gender } & \multicolumn{5}{|c|}{$\begin{array}{c}\text { Task E: } \\
\text { Clockwise (C) vs. Counterclockwise (CC) }\end{array}$} & \multicolumn{5}{|c|}{$\begin{array}{c}\text { Task C: } \\
\text { Left (L) vs. Right (R) }\end{array}$} \\
\hline & Direction & $M \mathrm{RT}$ & $\begin{array}{l}\text { Canon. } \\
\text { Orient. }\end{array}$ & Rate & $\%$ Var & Direction & MRT & $\begin{array}{l}\text { Canon. } \\
\text { Orient. }\end{array}$ & Rate & $\% \mathrm{Var}$ \\
\hline F & $\begin{array}{c}\mathrm{C} \\
\mathrm{CC}\end{array}$ & $\begin{array}{l}396 \\
471\end{array}$ & $\begin{array}{l}270 \\
330\end{array}$ & $\begin{array}{r}523 \\
1913\end{array}$ & $\begin{array}{l}64.3 \\
13.6\end{array}$ & $\begin{array}{l}\mathrm{L} \\
\mathrm{R}\end{array}$ & $\begin{array}{l}363 \\
487\end{array}$ & $\begin{array}{r}0 \\
90\end{array}$ & $\begin{array}{l}1200 \\
1278\end{array}$ & $\begin{array}{l}18.5 \\
37.5\end{array}$ \\
\hline $\mathbf{F}$ & $\begin{array}{c}\mathrm{C} \\
\mathrm{CC}\end{array}$ & $\begin{array}{l}355 \\
337\end{array}$ & $\begin{array}{r}300 \\
60\end{array}$ & $\begin{array}{r}915 \\
2002\end{array}$ & $\begin{array}{l}15.1 \\
15.7\end{array}$ & $\begin{array}{l}\mathrm{L} \\
\mathbf{R}\end{array}$ & $\begin{array}{l}370 \\
490\end{array}$ & $\begin{array}{r}0 \\
300\end{array}$ & $\begin{array}{l}773 \\
657\end{array}$ & $\begin{array}{l}41.2 \\
17.4\end{array}$ \\
\hline $\mathbf{F}$ & $\begin{array}{c}\mathrm{C} \\
\mathrm{CC}\end{array}$ & $\begin{array}{l}239 \\
266\end{array}$ & $\begin{array}{l}300 \\
270\end{array}$ & $\begin{array}{r}819 \\
1955\end{array}$ & $\begin{array}{l}48.3 \\
23.5\end{array}$ & $\begin{array}{l}\mathbf{L} \\
\mathbf{R}\end{array}$ & $\begin{array}{l}504 \\
489\end{array}$ & $\begin{array}{r}270 \\
90\end{array}$ & $\begin{array}{l}332 \\
377\end{array}$ & $\begin{array}{l}72.0 \\
59.9\end{array}$ \\
\hline $\mathbf{M}$ & $\begin{array}{c}\mathrm{C} \\
\mathrm{CC}\end{array}$ & $\begin{array}{l}576 \\
739\end{array}$ & $\begin{array}{l}210 \\
180\end{array}$ & $\begin{array}{l}465 \\
357\end{array}$ & $\begin{array}{l}40.2 \\
42.7\end{array}$ & $\begin{array}{l}\mathbf{L} \\
\mathbf{R}\end{array}$ & $\begin{array}{l}569 \\
542\end{array}$ & $\begin{array}{r}270 \\
60\end{array}$ & $\begin{array}{l}347 \\
389\end{array}$ & $\begin{array}{l}55.0 \\
42.7\end{array}$ \\
\hline$F$ & $\stackrel{\mathrm{C}}{\mathrm{CC}}$ & $\begin{array}{l}1032 \\
1464\end{array}$ & $\begin{array}{l}180 \\
150\end{array}$ & $\begin{array}{l}898 \\
171\end{array}$ & $\begin{array}{r}2.2 \\
16.6\end{array}$ & $\begin{array}{l}\mathrm{L} \\
\mathrm{R}\end{array}$ & $\begin{array}{l}1924 \\
2083\end{array}$ & $\begin{array}{r}180 \\
0\end{array}$ & $\begin{array}{l}217 \\
514\end{array}$ & $\begin{array}{l}7.7 \\
2.0\end{array}$ \\
\hline $\mathbf{M}$ & $\underset{\mathrm{CC}}{\mathrm{C}}$ & $\begin{array}{l}482 \\
497\end{array}$ & $\begin{array}{l}180 \\
180\end{array}$ & $\begin{array}{l}746 \\
917\end{array}$ & $\begin{array}{l}19.4 \\
25.8\end{array}$ & $\begin{array}{l}\mathbf{L} \\
\mathbf{R}\end{array}$ & $\begin{array}{l}467 \\
469\end{array}$ & $\begin{array}{l}0 \\
0\end{array}$ & $\begin{array}{l}517 \\
526\end{array}$ & $\begin{array}{l}39.7 \\
34.2\end{array}$ \\
\hline F & $\underset{\mathrm{CC}}{\mathrm{C}}$ & $\begin{array}{l}251 \\
374\end{array}$ & $\begin{array}{l}180 \\
240\end{array}$ & $\begin{array}{l}493 \\
526\end{array}$ & $\begin{array}{l}35.3 \\
24.4\end{array}$ & $\begin{array}{l}\mathbf{L} \\
\mathbf{R}\end{array}$ & $\begin{array}{l}395 \\
359\end{array}$ & $\begin{array}{r}270 \\
60\end{array}$ & $\begin{array}{l}642 \\
573\end{array}$ & $\begin{array}{l}33.8 \\
44.0\end{array}$ \\
\hline $\mathbf{F}$ & $\begin{array}{c}\mathrm{C} \\
\mathrm{CC}\end{array}$ & $\begin{array}{l}440 \\
554\end{array}$ & $\begin{array}{l}210 \\
120\end{array}$ & $\begin{array}{r}457 \\
1457\end{array}$ & $\begin{array}{l}50.7 \\
10.7\end{array}$ & $\begin{array}{l}\mathbf{L} \\
\mathbf{R}\end{array}$ & $\begin{array}{l}744 \\
790\end{array}$ & $\begin{array}{r}330 \\
60\end{array}$ & $\begin{array}{l}400 \\
250\end{array}$ & $\begin{array}{l}40.7 \\
52.3\end{array}$ \\
\hline F & $\begin{array}{c}\mathrm{C} \\
\mathrm{CC}\end{array}$ & $\begin{array}{l}453 \\
633\end{array}$ & $\begin{array}{l}240 \\
300\end{array}$ & $\begin{array}{r}1339 \\
852\end{array}$ & $\begin{array}{l}4.2 \\
0.7\end{array}$ & $\begin{array}{l}\mathrm{L} \\
\mathrm{R}\end{array}$ & $\begin{array}{l}720 \\
664\end{array}$ & $\begin{array}{r}210 \\
90\end{array}$ & $\begin{array}{l}360 \\
408\end{array}$ & $\begin{array}{l}32.1 \\
51.6\end{array}$ \\
\hline F & $\underset{\mathrm{CC}}{\mathrm{C}}$ & $\begin{array}{l}304 \\
371\end{array}$ & $\begin{array}{l}300 \\
240\end{array}$ & $\begin{array}{r}570 \\
3130\end{array}$ & $\begin{array}{r}37.0 \\
0.4\end{array}$ & $\begin{array}{l}\mathrm{L} \\
\mathrm{R}\end{array}$ & $\begin{array}{l}575 \\
589\end{array}$ & $\begin{array}{l}240 \\
330\end{array}$ & $\begin{array}{r}266 \\
1053\end{array}$ & $\begin{array}{r}37.5 \\
6.3\end{array}$ \\
\hline $\mathbf{M}$ & $\begin{array}{c}\mathrm{C} \\
\mathrm{CC}\end{array}$ & $\begin{array}{l}260 \\
250\end{array}$ & $\begin{array}{r}270 \\
60\end{array}$ & $\begin{array}{r}405 \\
2521\end{array}$ & $\begin{array}{r}58.0 \\
9.7\end{array}$ & $\begin{array}{l}\mathrm{L} \\
\mathrm{R}\end{array}$ & $\begin{array}{l}735 \\
715\end{array}$ & $\begin{array}{r}240 \\
90\end{array}$ & $\begin{array}{l}277 \\
305\end{array}$ & $\begin{array}{l}51.3 \\
61.5\end{array}$ \\
\hline $\mathbf{F}$ & $\begin{array}{c}\mathrm{C} \\
\mathrm{CC}\end{array}$ & $\begin{array}{l}353 \\
294\end{array}$ & $\begin{array}{l}270 \\
330\end{array}$ & $\begin{array}{l}1656 \\
3409\end{array}$ & $\begin{array}{l}14.4 \\
17.5\end{array}$ & $\begin{array}{l}\mathrm{L} \\
\mathrm{R}\end{array}$ & $\begin{array}{l}571 \\
537\end{array}$ & $\begin{array}{l}270 \\
120\end{array}$ & $\begin{array}{l}315 \\
566\end{array}$ & $\begin{array}{l}71.5 \\
48.8\end{array}$ \\
\hline $\mathbf{M}$ & $\begin{array}{c}\mathrm{C} \\
\mathrm{CC}\end{array}$ & $\begin{array}{l}318 \\
430\end{array}$ & $\begin{array}{l}\mathbf{0} \\
\mathbf{0}\end{array}$ & $\begin{array}{r}566 \\
1941\end{array}$ & $\begin{array}{r}57.4 \\
7.0\end{array}$ & $\begin{array}{l}\mathbf{L} \\
\mathrm{R}\end{array}$ & $\begin{array}{l}356 \\
413\end{array}$ & $\begin{array}{l}60 \\
30\end{array}$ & $\begin{array}{r}1558 \\
918\end{array}$ & $\begin{array}{l}41.8 \\
28.7\end{array}$ \\
\hline $\mathbf{M}$ & $\underset{\mathrm{CC}}{\mathrm{C}}$ & $\begin{array}{l}303 \\
324\end{array}$ & $\begin{array}{l}210 \\
180\end{array}$ & $\begin{array}{l}791 \\
956\end{array}$ & $\begin{array}{l}38.5 \\
37.3\end{array}$ & $\begin{array}{l}\mathbf{L} \\
\mathbf{R}\end{array}$ & $\begin{array}{l}584 \\
501\end{array}$ & $\begin{array}{l}210 \\
210\end{array}$ & $\begin{array}{l}677 \\
469\end{array}$ & $\begin{array}{l}34.2 \\
35.4\end{array}$ \\
\hline
\end{tabular}

Note-The first 7 subjects received Task E first. Canon. Orient. = canonical orientation. \% Var = proportion of variance accounted for. 
were expressed in relation to the canonical orientations as determined in the previous section. The orientations were numbered clockwise from the individual canonical orientations, so that the individual functions, insofar as they approximated mental-rotation functions, would be aligned with one another. The RTs were again subjected to an analysis of variance in which the independent variables were order, task, direction, and orientation, although it was only with respect to orientation and its interactions that this task differed from the previous one.

The effect of orientation was significant $[F(11,132)=$ $10.15, M S e=59,884, p<.001$ ], but this is not surprising since the orientations were effectively defined so as to maximize the effect of orientation. There was no longer a significant interaction between direction and orientation $[F(22,264)=0.88, M S e=50,655]$, which is again not surprising since the redefinition of orientation effectively compensates for the original effect. Of more interest was the interaction between task and orientation, but this remained insignificant $[F(11,132)=1.23$, $M S e=50,146]$. There was, however, a significant interaction between task and that component of orientation attributable to the idealized mental-rotation function $[F(1,132)=7.67, p<.01]$, and the residual was not significant $[F(10,132)=0.53]$. This can be interpreted to mean that the slope of the best fitting mental-rotation function differed between tasks. Separate analyses were therefore carried out for each task.

For Task $E$ the effect of orientation was significant $[F(11,132)=4.16, M S e=45,916, p<.001]$. The idealized mental-rotation function accounted for $83.78 \%$ of the variance, and the estimated rate of mental rotation was $708 \mathrm{dps}$. This value is within the range of estimates reported in previous studies, although it is toward the higher end. Cooper and Shepard (1973) reported individual variation from 180 to $800 \mathrm{dps}$, with a mean of $480 \mathrm{dps}$. However, Shepard and Hurwitz (1984) reported rotation rates falling between 600 and $700 \mathrm{dps}$ in judgments about left and right turns on a road map, in which the stimuli were effectively simple L-shapes, and Parsons (1987a, 1987b) obtained similar rates for mental rotation of body parts.

For Task $\mathrm{C}$, however, the estimated rotation rate was $439 \mathrm{dps}$, which is closer to the modal value from previous studies. The effect of orientation was again significant $[F(11,132)=7.46, M S e=64,114, p<.001]$, and the mental-rotation function accounted for $86.83 \%$ of the variance.

Further analysis of the influence of the direction of the jumps. In the foregoing analyses, it was assumed that, for Task $\mathrm{C}$, the jump had the effect of phase-shifting the mental-rotation function some $60^{\circ}-90^{\circ}$ in the direction opposite that of the jump. However, inspection of Figure 1 suggests that there may have been a second distorting influence, such that the maximum RT is shifted more than is the minimum. Note particularly that for leftward jumps, the maximum RT occurs at $15^{\circ}$, while the minimum is at $315^{\circ}$, a separation of only $60^{\circ}$. One possible reason for this is that subjects may have tended to mentally rotate in the direction of the jump rather than always taking the shortest angular distance to the canonical orientation (cf. Corballis \& McLaren, 1982). When this implies rotating more than $180^{\circ}$, I shall call it "overrotation." Thus, if a subject's maximum RT is $180^{\circ}+x^{\circ}$ from the minimum, and the direction from maximum to minimum is the same as that of the jump, then the degree of over-rotation is $x$.

The orientations of maximum and minimum RTs were determined for each direction for each subject. For leftward jumps, the minimum RTs for 11 of the 14 subjects were to jumps on the right side of the clock face, and the mean displacement was $47^{\circ}$ counterclockwise from the canonical orientation $\left(0^{\circ}\right)$. For rightward jumps, the minimum RTs for 9 of the 14 subjects were to jumps on the left of the clock face, but the mean displacement was only $2^{\circ}$ clockwise from the canonical orientation, suggesting minimal phase shift. When maximum RTs were considered, the degree of over-rotation varied from $0^{\circ}$ to $150^{\circ}$ for leftward jumps, with a mean of $62^{\circ}$, and varied from $-90^{\circ}$ (which might conceivably represent over-rotation of $270^{\circ}$, but is more likely an aberration due to noisy data) to $150^{\circ}$ for rightward jumps, with a mean of $26^{\circ}$. An analysis of variance, in which the independent variables were order and direction, showed that the mean over-rotation differed significantly from $0[F(1,12)=11.18, M S e=$ $4,832, p<.011$, but the effects of direction and order, and the interaction between them, were not significant.

A similar analysis for Task E yielded identical overrotation of $17^{\circ}$ for both clockwise and counterclockwise jumps, but this did not differ significantly from $0[F(1,12)$ $=1.11, \mathrm{MSe}=7,393]$.

\section{Discussion}

In the final analysis, the data do not entirely rule out mental rotation as a strategy in distinguishing clockwise from counterclockwise movement. Nevertheless, there were clear differences between the experimental and control tasks, suggesting that mental rotation was a less frequent strategy in the experimental task. These differences were as follows:

First, RTs were significantly shorter overall in the experimental task. The stimuli were the same in the two tasks, suggesting that the difference was not perceptual. One might have expected the response decision to have been faster, if anything, for Task $C$ than for Task E, since left-right discrimination is presumably more familiar than clockwise-counterclockwise discrimination. The difference presumably lies, therefore, in the intervening mental processes, suggesting that mental rotation was invoked more frequently in the control task.

Second, the data for individual subjects conformed better to idealized mental-rotation functions in the case of Task $C$ than in the case of Task $E$. When the functions were corrected for intersubject variations in the location 
of the supposed canonical orientation, both tasks produced reasonable approximations to an idealized mental-rotation function, suggesting that mental rotation may have been at least an occasional strategy in clockwise-counterclockwise judgments. However, the estimated rate of mental rotation in Task $\mathrm{E}$ was nearly double that in Task $\mathrm{C}$. Since there is no good reason to suppose that the actual rate of mental rotation would vary between tasks, the higher estimate for Task E probably reflects a lower incidence of mental rotation rather than a higher rate.

The assessment of mental rotation in this experiment was hindered to some extent by the distorting influence of the direction of the jump on the function relating RT to orientation, especially in Task C. Corballis and McLaren (1982) reported somewhat similar effects on the mental-rotation function induced by a rotation aftereffect, and suggested three possible mechanisms to explain it. Two of these mechanisms may be invoked to explain the present results.

First, the functions appear to have been phase shifted, such that the canonical orientation in Task $\mathrm{C}$ was somewhat in advance of the $0^{\circ}(6: 00)$ orientation, in the direction of the jump. This can be interpreted to mean that the subjects extrapolated the jump before initiating mental rotation. The analysis of shifts in the orientation producing minimum RTs suggested that this shift was more pronounced in the case of leftward (or clockwise) jumps than in the case of rightward (or counterclockwise) ones, perhaps because clockwise motion is the more familiar.

Second, subjects appear to have over-rotated in the direction of the jump. That is, they sometimes rotated through the larger angle to the canonical orientation when the jump was in that direction, rather than taking the more direct smaller angle. This over-rotation seems to have been more pronounced in the case of leftward (clockwise) jumps than in the case of rightward (counterclockwise) ones, and, although the difference was not significant, this may again reflect the greater familiarity with clockwise rotation.

These distorting influences were less discernible in the case of Task $E$, in part perhaps because of individual variations in the location of the canonical orientation. However, over-rotation was assessed independently of such variations and found to be statistically insignificant, although there was some evidence for it. Again, this can be interpreted as evidence that the incidence of mental rotation was at least reduced in Task E compared with that in Task C. It is also possible, however, that mental rotation was less affected by the direction of the jump in Task E than in Task C. The one subject (Subject 4) whose $\mathrm{RTs}$ were in reasonable conformity with mental rotation on both tasks was little influenced by the direction of the jump in Task $\mathrm{E}$, but strongly influenced in Task $\mathrm{C}$. In other respects, the fits and estimated rotation rates were very similar across tasks. It is not clear what it was about Task $\mathbf{C}$ that might have made it more susceptible to a directional influence.

\section{EXPERIMENT 2}

In this experiment, the direction of angular motion was represented in a static display, rather than in a dynamic one as in Experiment 1. The main purpose of this change was to remove any influence due to perceived motion itself.

\section{Method}

Subjects. The subjects were 6 women and 8 men, ranging in age from 18 to 50 years. All declared themselves to be right-handed, except for 2 left-handed women.

Stimuli and Equipment. The stimuli were again generated by an Apple Ile computer. Each stimulus consisted of a line $10 \mathrm{~cm}$ long, with a small square at one end and an arrow $5 \mathrm{~cm}$ long drawn at right angles from the other end. An example is shown in Figure 2. The small square can be regarded as a fulcrum, and was always located centrally on the screen. The line appeared in eight different orientations, in $45^{\circ}$ steps from the downward orientation. At each orientation, the arrow could point in either direction relative to the line. There were thus 16 different stimuli. On experimental trials, each stimulus was presented three times to make a total of 48 trials, except that if the subject made an error, that stimulus was repeated at the end of the series. The stimuli were presented in a different random order to each subject.

When the subject pressed a key to initiate a trial, a fixation dot appeared in the center of the screen, followed $500 \mathrm{msec}$ later by a stimulus, which remained on the screen until the subject responded. Presentation was synchronized with the onset of a TV frame, and RT was measured in milliseconds from the stimulus onset.

Tasks. There were two tasks. In Task E, the experimental task, the subject was instructed to press the $C$ key if the direction of the arrow on the stimulus indicated a clockwise direction of motion, and the $\mathrm{X}$ key if it indicated a counterclockwise direction. In Task C, the control task, the instruction was to press the $\mathrm{N}$ key if the arrow would be pointing to the right if the arrow were orientated downward from the fulcrum, and the B key if it would be pointing to the left. It was assumed that this task would involve mental rotation of the stimulus so that it was imagined as it would look when pointing downward. The labels "LEFT" and "RIGHT" were again affixed to the space bar underneath the $B$ and $N$ keys, respectively.

Procedure. Each subject received 10 randomly chosen practice trials, followed by the 48 experimental trials on each task. Half the subjects began with Task $\mathrm{E}$, half with Task $\mathrm{C}$. The subjects were again carefully instructed to follow instructions, and not to transform one task so that it was equivalent to the other. In all other respects, the procedure was the same as in Experiment 1.

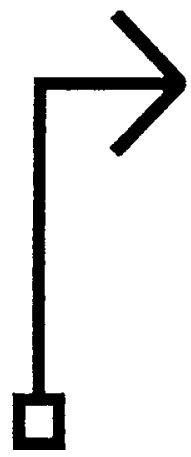

Figure 2. Example of clockwise, or left-pointing, stimulus in Experiment 2. 


\section{Results}

For the purposes of analysis, orientation was again measured from the downward orientation, which was defined as the canonical orientation in Task $\mathrm{C}$, in $45^{\circ}$ clockwise steps.

Errors. Errors were subjected to analysis of variance, with task, order, orientation, and direction as dependent variables. The only significant effect was that there were more errors on Task E (8.04\%) than on Task C $(4.91 \%)$ $[F(1,12)=5.33, M S e=0.1845, p<.05]$. Again, the correlations across the eight orientations between the mean number of errors and mean RTs were positive, . 40 for Task E and .70 for Task C, indicating that RT trends were probably not contaminated by speed-accuracy trade-offs.

Reaction times. An analysis of variance of RTs revealed a significant main effect of orientation $[F(7,84)=$ $11.22, M S \mathrm{e}=32,701, p<.001]$, as well as a significant interaction between task and orientation $[F(7,84)=$ $8.88, M S e=26,376, p<.001]$. There was also a significant effect of direction $[F(2,24)=7.74, M S e=$ $31,105, p<.01$ ], which was due largely to the shorter mean RT for clockwise (712 msec) than for counterclockwise $(800 \mathrm{msec})$ decisions in Task $\mathrm{E}[t(24)=4.01, p<$ $.001]$. Although "right" decisions $(751 \mathrm{msec})$ were faster than "left" decisions ( $778 \mathrm{msec})$, the difference was not significant $[t(24)=1.18]$. The mean RTs were $755 \mathrm{msec}$ for Task E and $764 \mathrm{msec}$ for Task C, and, unlike in Experiment 1 , the difference was not significant $[F(1,12)=$ $0.04, M S e=175,718]$.

Mean RTs for each task at each orientation are plotted in Figure 3. The function clearly implies mental rotation in the case of Task C, but not in the case of Task E. A contrast representing an idealized mental-rotation function, assuming the canonical orientation to be the 6:00 orientation, was defined by the coefficients $-2,-1,0$, $1,2,1,0$, and -1 , counting clockwise from the downward orientation. This was fitted to the RTs at each orientation for each task. For Task C, it accounted for $95.77 \%$ of the variance and yielded an estimated mental-rotation rate of $423 \mathrm{dps}$, which is within expected bounds (Cooper \& Shepard, 1973). For Task E, the percentage of variance explained was only $26.23 \%$, and the estimated rate was $3,484 \mathrm{dps}$; these parameters are clearly inconsistent with mental rotation.

Fits to individual data. Again, one reason for the flattened function for Task $\mathrm{E}$ may have been that subjects chose different canonical orientations. Consequently, the contrast representing mental rotation was fitted to the RTs of each subject in turn, with the canonical orientation systematically rotated through each $45^{\circ}$ orientation. The canonical orientation yielding the best fit was defined as the canonical orientation for that subject. This was done for both tasks, and the individual results are summarized in Table 2 .

The canonical orientations were indeed more variable for Task $E$ than for Task $C$. On Task $C$, all but 2 of the subjects mentally rotated the stimuli to the $0^{\circ}$ (or 6:00) orientation, in conformity with instructions; for the other two (Subjects 2 and 4), the canonical orientation was at $45^{\circ}$ ( $7: 30$ on the clock face). Not only was the canonical orientation more variable for Task $\mathrm{E}$, but it was also influenced by Task $C$ if Task $C$ preceded Task E: 3 of the subjects who received Task $C$ first rotated to the $0^{\circ}$ orientation on Task $\mathrm{E}$, compared with none of those who received Task E first. Some subjects may therefore have performed Task $E$ by choosing some canonical orientation as defining the two shapes as static templates, and mentally rotating each shape to that orientation for matching against these templates. This, in turn, suggests that subjects may not have found it easy to make judgments of angular direction independently of orientation.

It is also apparent that the individual data are better fit by the mental-rotation function than are those of Experiment 1 , probably because of the distorting influence of the direction of the jump in the earlier experiment. If we adopt the lenient definition of a mental rotator used in Ex-

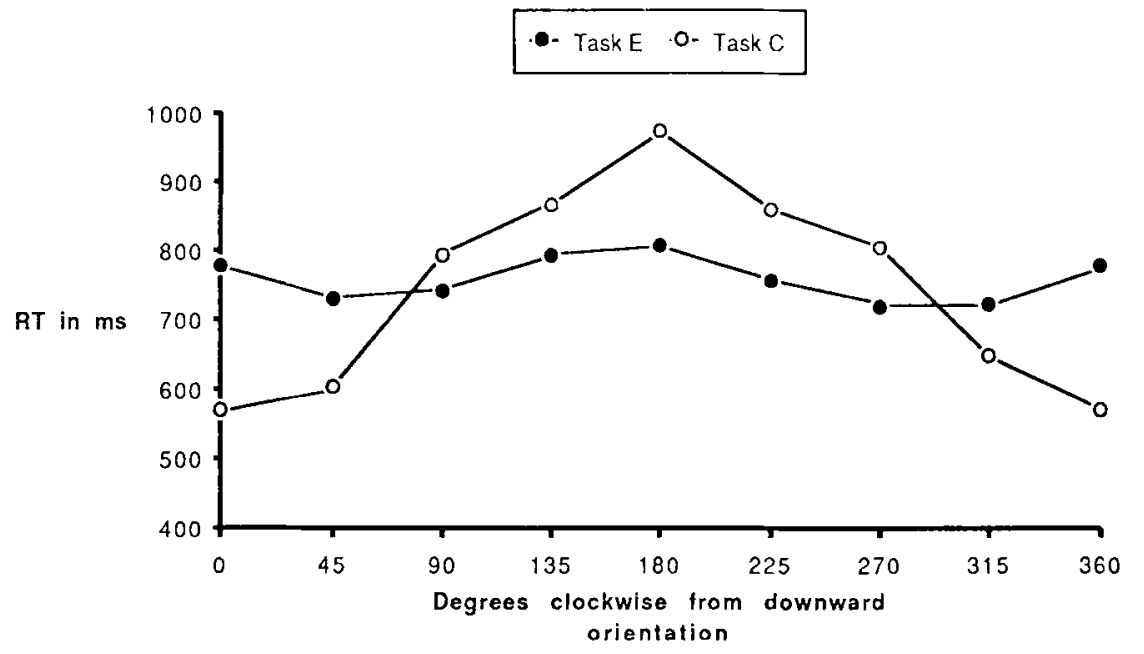

Figure 3. Mean RT as a function of angular distance from downward orientation, for each task in Experiment 2. 
Table 2

Individual Parameters in Experiment 2

\begin{tabular}{|c|c|c|c|c|c|c|c|c|}
\hline \multirow[b]{2}{*}{ Gender } & \multicolumn{4}{|c|}{$\begin{array}{c}\text { Task E: } \\
\text { Clockwise vs. Counterclockwise }\end{array}$} & \multicolumn{4}{|c|}{$\begin{array}{c}\text { Task C: } \\
\text { Left vs. Right }\end{array}$} \\
\hline & $M \mathrm{RT}$ & $\begin{array}{l}\text { Canon. } \\
\text { Orient. }\end{array}$ & Rate & \% Var & $M \mathrm{RT}$ & $\begin{array}{l}\text { Canon. } \\
\text { Orient. }\end{array}$ & Rate & $\%$ Var \\
\hline $\mathbf{M}$ & 622 & 180 & 584 & 82.1 & 553 & 0 & 683 & 87.2 \\
\hline $\mathbf{M}$ & 632 & 180 & 765 & 55.0 & 656 & 45 & 584 & 71.9 \\
\hline $\mathbf{F}$ & 775 & 315 & 283 & 87.5 & 632 & 0 & 359 & 85.9 \\
\hline $\mathbf{F}$ & 946 & 45 & 606 & 40.2 & 856 & 45 & 428 & 51.6 \\
\hline $\mathbf{M}$ & 570 & 315 & 745 & 68.3 & 573 & 0 & 631 & 75.1 \\
\hline$F$ & 658 & 225 & 387 & 70.5 & 775 & 0 & 341 & 89.0 \\
\hline $\mathbf{M}$ & 825 & 180 & 701 & 51.7 & 756 & 0 & 372 & 65.2 \\
\hline $\mathbf{M}$ & 954 & 135 & 1765 & 5.9 & 1061 & 0 & 693 & 31.5 \\
\hline $\mathbf{F}$ & 581 & 0 & 619 & 87.6 & 874 & 0 & 322 & 70.7 \\
\hline F & 1047 & 0 & 683 & 27.5 & 775 & 0 & 366 & 78.4 \\
\hline F & 572 & 225 & 1294 & 47.6 & 815 & 0 & 293 & 78.8 \\
\hline $\mathbf{M}$ & 964 & 45 & 779 & 30.8 & 910 & 0 & 352 & 72.6 \\
\hline$F$ & 733 & 315 & 559 & 68.7 & 776 & 0 & 546 & 49.4 \\
\hline $\mathbf{F}$ & 703 & 0 & 503 & 77.4 & 688 & 0 & 414 & 73.0 \\
\hline
\end{tabular}

Note-The first 7 subjects received Task E first. Canon. Orient. = canonical orientation. \% Var = proportion of variance accounted for.

periment 1 , then all 14 subjects resorted to mental rotation on Task C, and 12 of the 14 did so on Task E. A more stringent definition, and one that more effectively discriminates the groups, is to label a subject a mental rotator on one or the other task if (1) the proportion of variance accounted for is at least 0.6 , and (2) the estimated rate of mental rotation is less than $800 \mathrm{dps}$. According to these two criteria, 11 of the subjects resorted to mental rotation on Task C, compared with only 7 on Task E. It seems reasonable to conclude again that mental rotation was a less frequent strategy when subjects judged angular direction than when they judged left versus right.

Analysis of adjusted orientation functions. As in Experiment 1 , the orientation functions were again aligned by numbering the orientations clockwise from the canonical orientation estimated for each subject. This was done separately for each task. The analysis of variance of $R T$ s was then repeated. Of critical interest was the interaction between task and orientation, which was significant $[F(7,84)=2.31, M S e=18,549, p<.05]$. Moreover, the interaction between task and that component of orientation attributable to the mental-rotation function was also significant $[F(1,84)=10.58, p<.001]$, leaving an insignificant residual $[F(6,84)=0.93]$. Mean RTs for each task at each orientation are shown in Figure 4.

The idealized mental-rotation function accounted for $87.37 \%$ of the variance in Task $E$ and $96.59 \%$ in Task C. The estimated rates of mental rotation were 618 and $421 \mathrm{dps}$, respectively. Thus, Task $\mathrm{C}$ yielded the better approximation to a mental-rotation function, even when the data were corrected for variations in the canonical orientation. Indeed, the corrected data for Task $\mathrm{E}$ were poorer than the uncorrected data for Task C. This further suggests that mental rotation was the more frequent strategy in the control task. Even so, many of the subjects did seem to resort to mental rotation in making clockwise versus counterclockwise judgments.

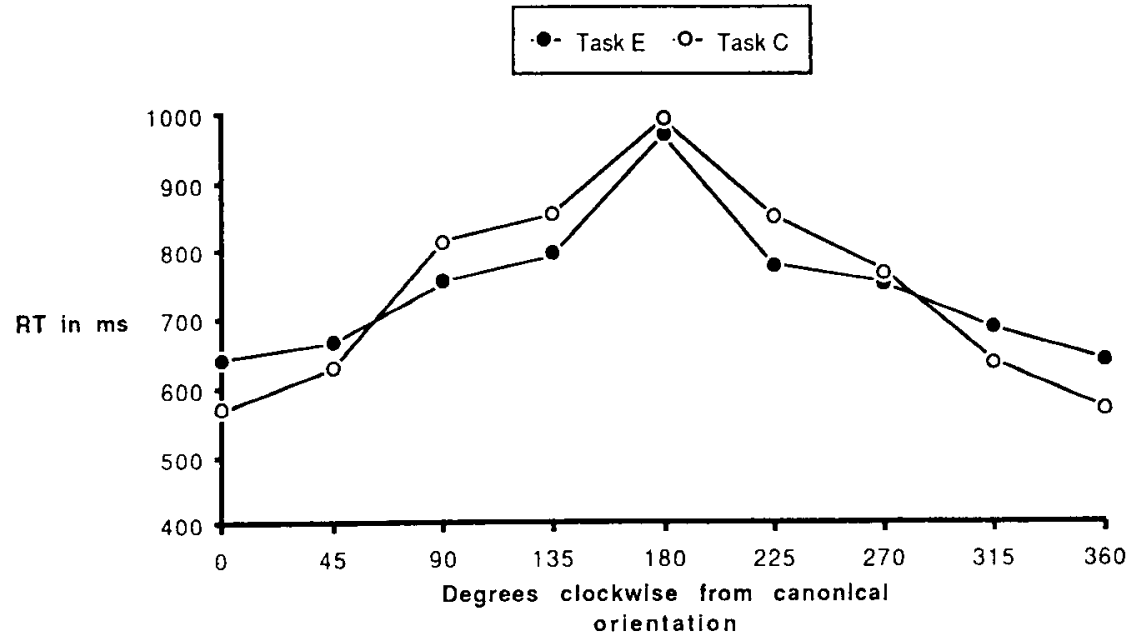

Figure 4. Mean RT as a function of angular distance from empirically determined canonical orientations, for each task in Experiment 2. 


\section{Discussion}

In Experiment 1, the assessment of mental rotation was hindered by distortions introduced by the dynamic displays. This was overcome in Experiment 2 by the use of static displays, resulting in better fits to an idealized mental-rotation function. The data suggest again that the incidence of mental rotation was at least reduced when subjects were instructed to judge whether stimuli were clockwise or counterclockwise than when instructed to judge their parity, or left-right sense, relative to a given canonical orientation. It remains conceivable, though, that subjects did adopt mental rotation as often in Task $E$ as in Task $\mathrm{C}$, but that the canonical orientation adopted in Task E fluctuated between trials. In any event, mental rotation remained a fairly common strategy even in Task $\mathrm{E}$, and access to an orientation-free sense of angular direction, although probably present for some of the subjects some of the time, remains fairly elusive.

\section{EXPERIMENT 3}

The next question was whether subjects might be able to use an orientation-free code to discriminate normal from backward letters, if suitably instructed.

\section{Method}

Subjects. This experiment was run as a laboratory exercise in a second-year undergraduate class in cognitive psychology at the University of Auckland. One hundred students participated for credit in the course, but the data from 18 of them were discarded because they made $20 \%$ or more errors on the experimental trials.

The subjects were organized into eight laboratory sections. Four sections were given instructions to judge the letters as clockwise or counterclockwise (experimental task, or Task E), as explained below, and the other four were told to judge them as normal or backward (control task, or Task C). There were 41 subjects assigned to each task in this way. Those receiving Task E comprised 15 men and 26 women ranging in age from 18 to 45 years, with a mean age of 21.8 years. Those receiving Task $C$ comprised 9 men and 32 women ranging in age from 18 to 42 years, with a mean of 22.7 . Three subjects in the Task E group and 4 in the Task $C$ group described themselves as left-handed. The remaining subjects described themselves as right-handed.

Stimuli and Apparatus. Experiment 3, like the first two, was controlled by Apple Ile computers. The stimuli were the uppercase letters $F, P$, and $R$, each presented in normal and backward versions in each of eight angular orientations, ranging from $0^{\circ}$ to $315^{\circ}$ clockwise from the normal upright in $45^{\circ}$ steps. There were thus 48 different stimuli, and each was presented twice to make an experimental sequence of 96 trials. The stimuli were presented in a different random order to each subject. Each letter was $10 \mathrm{~mm}$ high and was viewed from about $0.71 \mathrm{~cm}$.

Before each trial, a small fixation cross appeared in the center of the screen. This disappeared when the subject pressed a key to initiate the trial, and was followed after $500 \mathrm{msec}$ by the stimulus for that trial, which remained on the screen until the subject responded.

Tasks and Procedure. For Task E the subjects were told to decide whether each letter represented a clockwise or a counterclock wise angular direction, depending on which way the protruding bulk of the letter was oriented relative to the main axis of the letter. The letters used, F, P, and R, represent a clockwise direction by this definition, and their backward equivalents represent a counterclockwise direction. To illustrate this, it was suggested that subjects might imagine an airplane propeller attached to the outside of the rounded portion of the $P$ and $R$, or to the end of the top strut of the $F$, and a fulcrum or hinge at the bottom end of the downstroke. Drawings of these appendages were shown to the subjects, with the letters in various orientations. A propeller so mounted would tend to rotate the normal versions clockwise and the backward versions counterclockwise. The subjects were told to try not to treat the stimuli as letters, but rather as potentially rotating objects. They appeared to have no difficulty in understanding what was required.

The instructions were given to each laboratory section as a whole, and were repeated and embellished as long as was necessary for all subjects present in the section to understand. The subjects were also asked not to reveal the instructions they had received to other students in the course.

Subjects in the sections receiving Task $\mathrm{C}$ were simply asked to decide whether each letter was normal or backward, as in the standard mental-rotation task described by Cooper and Shepard (1973). The keys used for responses were the same as in the previous two experiments.

On test trials themselves, the subjects worked individually in cubicles. Each received a minimum of 10 practice trials, randomly chosen from the stimulus set, before embarking on the 96 experimental trials. If an error was made, the stimulus was repeated at the end of the sequence. Those who had performed Task E were asked at the end if they thought they had managed to follow the instructions successfully.

\section{Results}

For the purposes of analysis, angular orientation was measured clockwise from the normal upright.

Errors. Analysis of variance of the errors revealed that subjects made significantly more errors on Task $\mathrm{E}$ $(9.57 \%)$ than on Task $\mathrm{C}(6.70 \%)[F(1,80)=6.89, \mathrm{MSe}$ $=1.4129, p<.05]$. More subjects were also discarded from Task E (12) than from Task C (8) because of high error rates. The subjects also made significantly more errors to normal $(9.68 \%)$ than to backward $(6.61 \%)$ letters $[F(1,80)=16.16, M S e=0.6905, p<.01]$. Errors increased systematically with angular departure from the normal upright $[F(7,560)=30.82, M S e=0.7244, p<$ .001 ], rising from $2.86 \%$ for upright letters to $21.1 \%$ for inverted ones.

There were also significant interactions between task and version $[F(1,80)=8.74, M S \mathrm{e}=0.6905, p<.01]$, task and orientation $[F(7,560)=3.47, M S \mathrm{e}=0.7244$, $p<.01]$, version and orientation $[F(7,560)=6.28, M S \mathrm{e}$ $=0.6440, p<.001]$, and task, version, and orientation $[F(7,560)=30.82, M S \mathrm{e}=0.7244, p<.001]$. Means for each orientation, task, and version are shown in Table 3 , and indicate the nature of these interactions.

Reaction times. An analysis of variance of RTs for correct decisions revealed no significant difference between tasks $[F(1,80)=0.43$, MSe $=2,047,207]$ : the means were $951 \mathrm{msec}$ for Task $\mathrm{C}$ and $1,002 \mathrm{msec}$ for Task E. RT to normal (clockwise) letters $(884 \mathrm{msec})$ was significantly shorter than that to backward (counterclockwise) letters $(1,069 \mathrm{msec})[F(1,80)=59.49, M \mathrm{Se}=190,643$, $p<.001]$, and the difference was significantly more pronounced on Task E $(236 \mathrm{msec})$ than on Task C 
Table 3

Mean Percent Errors for Each Decision at Each

Orientation for Each Task in Experiment 3

\begin{tabular}{cccccccccc}
\hline & & \multicolumn{6}{c}{ Orientation (Degrees Clockwise from Normal Upright) } \\
\cline { 2 - 10 } Task & Decision & \multicolumn{1}{c}{$0^{\circ}$} & $45^{\circ}$ & $90^{\circ}$ & $135^{\circ}$ & $180^{\circ}$ & $225^{\circ}$ & $270^{\circ}$ & $315^{\circ}$ \\
\hline Task E & $\mathrm{C}$ & .41 & 4.47 & 4.47 & 18.29 & 36.59 & 19.11 & 9.76 & 4.88 \\
& $\mathrm{CC}$ & 5.28 & 2.85 & 3.66 & 8.13 & 15.85 & 8.94 & 6.91 & 3.66 \\
Task C & $\mathrm{N}$ & 2.03 & 4.88 & 4.06 & 13.01 & 17.07 & 10.16 & 2.85 & 2.85 \\
& $\mathrm{~B}$ & 3.66 & 5.69 & 5.28 & 6.91 & 15.04 & 4.88 & 3.66 & 5.28 \\
\hline
\end{tabular}

$(136 \mathrm{msec})[F(1,80)=4.29, M S \mathrm{e}=190,643, p<.05]$. There was also a significant main effect of orientation $[F(7,560)=78.25, M S e=74,741, p<.001]$.

The interaction between task and orientation was not significant $[F(7,560)=1.59, M S e=74,741]$. As in Experiment 2 , however, a contrast representing an idealized mental-rotation function was defined by the coefficients $-2,-1,0,1,2,1,0$, and -1 , corresponding to the orientations measured clockwise from the normal upright. The interaction between task and the component of orientation attributable to this contrast was significant $[F(1,560)$ $=6.29, p<.05]$, leaving an insignificant residual $[F(6,560)=0.80]$. This can be interpreted to mean that the tasks differed with respect to either the rate or the incidence of mental rotation that they induced.

Fitting the mental-rotation contrast separately to the RTs for each task yielded estimated rotation rates of $286 \mathrm{dps}$ for Task C and $356 \mathrm{dps}$ for Task E. The contrast accounted for $95.81 \%$ and $96.83 \%$ of the variance, respectively. The orientation functions for each task are plotted in Figure 5.

Fits to individual data. As in the previous experiments, the mental-rotation contrast was fit cyclically to the RTs for each subject, to yield estimates of mental-rotation rate and variance accounted for relative to canonical orientation providing the best fit.

For Task $\mathrm{C}$ the contrast provided a good fit in nearly every case. For 32 of the 41 subjects, the canonical orien- tation was at $0^{\circ}$ (the normal upright), whereas for the remaining 9 it was at either $315^{\circ}$ (8 subjects) or $45^{\circ}$ (1 subject). For 1 subject the estimated rate was $888 \mathrm{dps}$ and the variance accounted for was $37.84 \%$; for the rest, the rates ranged from 113 to $869 \mathrm{dps}$ and the variances from $55.29 \%$ to $93.19 \%$.

On Task E, 4 subjects showed a poor fit to the idealized mental-rotation function; their canonical orientations were estimated to lie at $180^{\circ}, 135^{\circ}, 135^{\circ}$, and $225^{\circ}$; their rotation rates were estimated at $2,236,2,264,1,925$, and $809 \mathrm{dps}$; and the variances accounted for by the mentalrotation function were $12.24 \%, 21.62 \%, 26.23 \%$, and $22.75 \%$, respectively. These subjects, who were all men (one of them left-handed), may have been able to discriminate clockwise from counterclockwise letters, as instructed, and on the basis of an orientation-free code. For the remaining 37 subjects, however, the estimates were comparable to those for Task C. For 28 , the canonical orientation was at $0^{\circ}$; for the others, it was either at $315^{\circ}$ ( 3 subjects) or at $45^{\circ}$ ( 6 subjects). Estimated rates ranged from 79 to $793 \mathrm{dps}$, and variance accounted for from $44.14 \%$ to $94.23 \%$.

The mental-rotation parameter estimates were also subjected to a least-squares analysis of variance, in which the independent variables were task, gender, and handedness. With percentage of variance accounted for as the dependent variable, there was a significant difference between tasks $[F(1,74)=9.75, M S \mathrm{e}=21,990, p<.01]$;

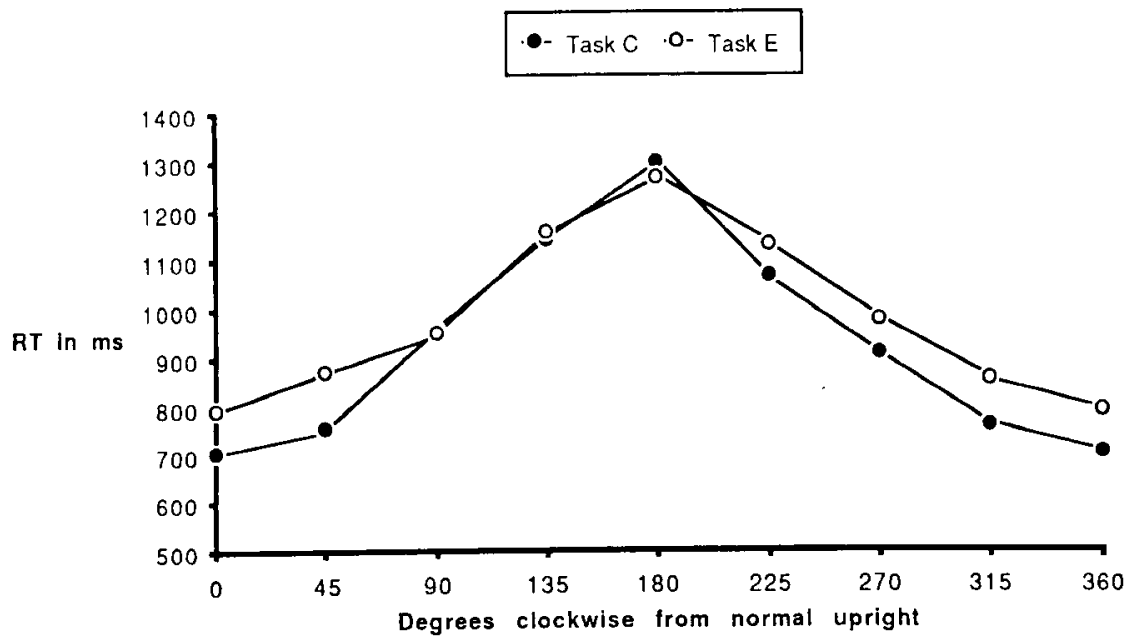

Figure 5. Mean RT as a function of angular orientation, measured from normal upright, in Experiment 3. 
the means, adjusted for differences in handedness and gender, were 76.94 and 56.49 for Task $C$ and Task E, respectively. There was also a significant effect of gender $[F(1,74)=4.52, M S \mathrm{e}=21,990, p<.05]$, but a significant interaction between task and gender showed that this difference was restricted primarily to Task $\mathrm{E}[F(1,74)$ $=14.63, M S e=21,990, p<.001]$. The means for men and women were 82.50 and 71.38 , respectively, on Task $C$ and 37.01 and 75.98 , respectively, on Task E. This reflects the fact that the 4 subjects in Task $E$ who most conspicuously failed to conform to the mentalrotation contrast were all men. A significant interaction between task, gender, and handedness $[F(1,74)=4.54$, $M S \mathrm{e}=21,990, p<.05]$ reflects the fact that the sole left-handed man in Task $E$ was one of these 4.

The tasks also differed significantly with respect to estimated rate of mental rotation $[F(1,74)=11.94, M S e$ $=96,034, p<.01]$; the adjusted means were 426 and 918 dps for Tasks $C$ and $E$, respectively. There was a significant effect of gender $[F(1,74)=16.42, M S \mathrm{e}=$ $96,034, p<.001$ ], but a significant task $\times$ gender interaction reflected the fact that this was restricted largely to Task $\mathrm{E}[F(1,74)=17.32, M S \mathrm{e}=96,034, p<.001]$. The adjusted means for men and women were 419 and $434 \mathrm{dps}$, respectively, on Task C, and 1,461 and $337 \mathrm{dps,}$ respectively, on Task E. Once again, the triple interaction between task, gender, and handedness $[F(1,74)=$ $7.32, M S e=96,034, p<.01]$ reflected the influence of the sole left-handed man in Task $E$ who failed to conform to the mental-rotation function.

None of the subjects who performed Task E claimed to have been unable to follow the instructions, although 8 professed to be unsure. The results remained substantially the same when these subjects were removed from the analysis. In particular, the difference between tasks on both variance accounted for and estimated rotation rate remained significant when corrected for handedness and gender differences between groups $[F(1,66)=5.80$ and 10.42 , respectively, $M S \mathrm{e}=101,756, p<.01]$.

Summary. The RTs conformed more closely to the hypothesis of mental rotation in the case of Task $\mathrm{C}$ than in the case of Task E. However, the difference was largely attributable to 4 male subjects who were apparently able to judge whether letters were clockwise or counterclockwise without resort to mental rotation. The great majority of subjects did appear to adopt a mental-rotation strategy, regardless of the task.

\section{GENERAL DISCUSSION}

In all three experiments, there was evidence that mental rotation was invoked in the discrimination of clockwise from counterclockwise by at least some subjects some of the time. However, the estimated rates of mental rotation were, in each case, significantly higher in the experimental than in the control tasks, even when individual RT functions were adjusted to compensate for differences in the choice of canonical orientation. This was probably due to a lowered incidence of mental rotation rather than to a higher rate.

Conversely, the subjects were more often able to judge clockwise versus counterclockwise directions without mental rotation than they were able to perform the control tasks without mental rotation. To the extent that this was so, it may be said that they had access to an orientation-free parity code. However, access to such a code declined over the three experiments. Subjects appeared best able to tell clockwise from counterclockwise without mental rotation in Experiment 1, involving representation of movement on a clock face. Mental rotation was invoked more frequently in Experiment 2, where angular direction was represented in static displays. It was invoked by nearly all subjects in Experiment 3, where subjects were asked to discriminate normal from backward versions of the letters F, P, and R in terms of an implied angular direction. The data from this experiment suggested a gender difference in that the 4 subjects who were able to use the instructed orientation-free code were all males. There was no evidence for a gender difference in rate of mental rotation on the control task, requiring that the versions be discriminated as normal versus backward.

Although the results suggest that access to an orientation-free parity code is somewhat limited, it should be noted that such a code is always in competition with an orientation-contingent code; that is, the discrimination of clockwise from counterclockwise can always be accomplished by establishing some canonical orientation, and then mentally rotating the stimuli to that orientation for reference to canonical versions. In deciding whether a particular rotation is clockwise or counterclockwise, for instance, it may be more efficient to judge the motion relative to some particular orientation, such as the upward or 12:00 orientation, than to attempt an orientation-free judgment. This may be especially so in the case of judgments about letters, where there is a natural canonical orientation. In this respect, then, the present experiments may underestimate people's ability to make judgments about angular direction independently of orientation. Mental rotation to some canonical orientations may have simply proved faster and more efficient, notwithstanding the extra time component due to mental rotation itself.

Whether or not mental rotation is invoked in mirrorimage discriminations may depend in part on the nature of the stimuli and the subjects' previous experience with them. Thus, access to orientation-free information about the distinction between clockwise and counterclockwise directions may have been most frequent precisely when the stimuli depicted a hand on a clock face; one's experience in reading times on a clock face is presumably relatively unbiased with respect to the positions of the hands. By contrast, access to an orientation-free code was least frequent when the stimuli were letters, which are nearly always seen at or near the upright orientation.

There still seems something of a discrepancy between the present results and previous evidence that the recog- 
nition of normal alphanumeric characters is faster than recognition of backward ones, independently of orientation and in the absence of mental rotation (Corballis et al., 1978; Corballis \& Nagourney, 1978; Corballis et al., 1985). This evidence suggests the fairly direct influence of an orientation-free parity code. It may be important to distinguish between the influence of a code in recognition or categorization, on the one hand, and access to that code for the purposes of explicit discrimination, on the other.

\section{REFERENCES}

BAteson, G. (1980). Mind and nature: A necessary unity. Glasgow, Scotland: Fontana/Collins.

Cavanagh, J. P., Anstis, S. M. (1980). Visual psychophysics on the Apple II: Getting started. Behavior Research Methods \& Instrumentation, 12, 614-626.

COOPER, L. A., Podgorny, P. (1976). Mental transformations and visual comparison processes: Effects of complexity and similarity. Joumal of Experimental Psychology: Human Perception \& Performance, 2, 503-514.

COOPER, L. A., Shepard, R. N. (1973). Chronometric studies of the rotation of mental images. In W. G. Chase (Ed.), Visual information processing (pp. 75-176). New York: Academic Press.

COOPER, L. A., SHEPARD, R. N. (1975). Mental transformation in the identification of left and right hands. Joumal of Experimental Psychology: Human Perception \& Performance, 1, 48-56.

Corbalus, M. C. (1982). Mental rotation: Anatomy of a paradigm. In M. Potegal (Ed.), Spatial abilities: Developmental and physiological foundations (pp. 173-198). New York: Academic Press.

Corballus, M. C. (1988). Recognition of disoriented shapes. Psychological Review, 95, 115-123.

Corballis, M. C., Beale, I. L. (1976). The psychology of lefi and right. Hillsdale, NJ: Erlbaum.

Corballus, M. C., Macadie, L., Crotty, A., Beale, I. L. (1985).
The naming of disoriented letters by normal and reading-disabled children. Joumal of Child Psychology \& Psychiatry, 10, 318-327.

Corballus, M. C., McLaren, R. (1982). Interaction between perceived and imagined rotation. Journal of Experimental Psychology: Human Perception \& Performance, 8, 215-224.

Corballis, M. C., Nagourney, B. A. (1978). Latency to categorize disoriented alphanumeric characters as letters or digits. Canadian Joumal of Psychology, 23, 186-188.

Corballus, M. C., Zbrodof, N. J., Shetzer, L. I., \& Butler, P. B. (1978). Decisions about identity and orientation of rotated letters and digits. Memory \& Cognition, 6, 98-107.

ELEY, M. G. (1982). Identifying rotated letter-like symbols. Memory \& Cognition, 10, 25-32.

Hinton, G. E., \& Parsons, L. M. (1981). Frames of reference and mental imagery. In A. D. Baddeley \& J. Long (Eds.), Attention and performance IX (pp. 261-278). Hillsdale, NJ: Erlbaum.

JoLICOEUR, P. (1985). The time taken to name disoriented natural objects. Memory \& Cognition, 13, 289-303.

LEPORI, N. G. (1969). Sur la genèse des structures asymétriques chez l'embryon des oiseaux. Monitore Zoologico Italiano, 3, 33-53.

ORTON, S. T. (1937). Reading, writing, and speech problems in children. New York: Norton.

Parsons, L. (1987a). Imagined spatial transformation of one's body. Journal of Experimental Psychology: General, 116, 172-191.

Parsons, L. (1987b). Imagined spatial transformations of one's hands and feet. Cognitive Psychology, 19, 178-241.

SChwartz, S. P. (1981). The perception of disoriented complex objects. Unpublished manuscript, Yale University, New Haven, CT.

SHEPARD, R. N., \& HURwrTz, S. (1984). Upward direction, mental rotation, and discrimination of left and right turns in maps. Cognition, 18, 161-193.

WHITE, M. J. (1980). Naming and categorization of tilted alphanumeric characters do not require mental rotation. Bulletin of the Psychonomic Society, 15, 153-156.

(Manuscript received August 17, 1987; revision accepted for publication February 23,1988 .) 